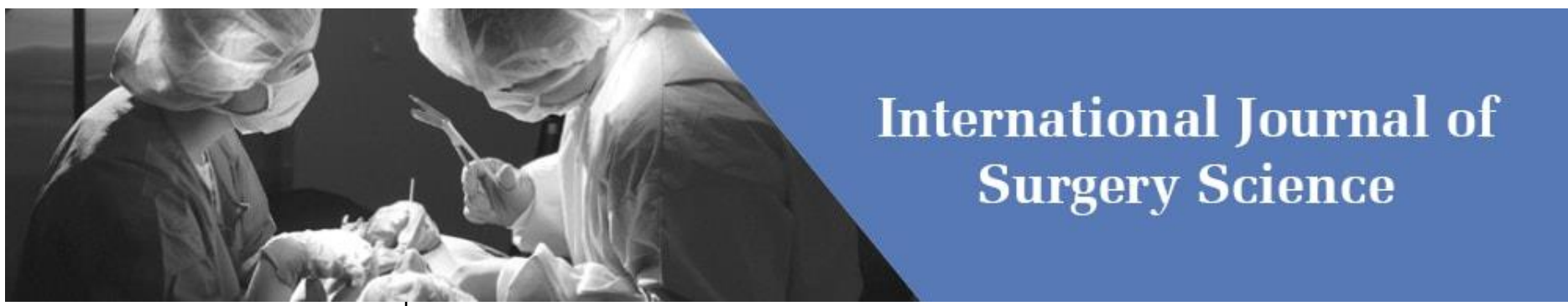

E-ISSN: 2616-3470

P-ISSN: 2616-3462

(C) Surgery Science

www.surgeryscience.com

2020; 4(4): 304-309

Received: 30-11-2020

Accepted: 22-12-2020

Deepak Kumar Bhojwani

Assistant Professor, Chirayu

Medical College \& Hospital,

Bhopal, Madhya Pradesh, India

Kiran Dodani

Professor and HOD, Department of Periodontology, RKDF Dental College and Research Centre,

Bhopal, Madhya Pradesh, India

\section{A prospective cross - Sectional investigation of the clinical characteristics features and management of lower limb ulcers}

\author{
Deepak Kumar Bhojwani and Kiran Dodani
}

DOI: https://doi.org/10.33545/surgery.2020.v4.i4e.676

\section{Abstract}

Aim: To determine the clinical features and management of ulcers of the lower limb.

Methods: The Department of General Surgery conducted a prospective cross-sectional analysis. With the aid of computer-generated random numbers, 100 patients with chronic leg ulcers were chosen at random from those who visited the OPD or were admitted to the surgical ward. After determining the primary cause of leg ulcers, proper antibiotic coverage for gram positive, gram negative, and anaerobic organisms, proper glycaemic control, leg elevation, compression bandaging, total cessation of smoking and causative drugs, nutritional support, vasoactive agents to restore blood flow, nerve stimulation, and proper wound care with debridement slough excision are also recommended.

Results: The leg ulcers were more prevalent in the age group $40-70$ years. Test of proportion showed that proportion of males $85 \%$ was significantly higher than that of females $15 \%(Z=9.74 ; p<0.0001)$. Thus the leg ulcers were more prevalent among males. Ulcers in the left leg $(49 \% 0$ was higher than that of right leg $(47 \%)$ but it was not significant $(\mathrm{Z}=0.28 ; \mathrm{p}=0.77)$. Only $3 \%$ of the patients were having ulcers in both legs. Most of the patients $(61 \%)$ had ulcer at foot followed by gaiter $(20 \%)$ and leg $(19 \%)$. $(Z=6.14 ; p<0.0001)$. Most of the ulcers were diabetic $(37 \%)$ followed by venous $(22 \%)(\mathrm{Z}=2.31 ; \mathrm{p}=0.01)$. Only $5 \%$ and $3 \%$ were malignant and trophic ulcers.

Conclusion: There has undoubtedly been a significant increase in the treatment of untreated leg ulcers, thanks to the availability of an array of investigational antibiotics and ever-improving dressing materials.

Keywords: Lower limb ulcer, Leg ulcer, chronic ulcer, Ulcer treatment

\section{Introduction}

A chronic leg ulcer (CLU), also known as a chronic lower limb ulcer, is a chronic wound on the leg that does not heal after three months of effective therapy or is not completely healed after a year ${ }^{[1]}$. Because of the ageing population and elevated risk factors for atherosclerotic occlusion including smoking, obesity, and diabetes, the rate of ulceration is increasing. Wounds with a "full thickness diameter" and a "late healing propensity" are classified as ulcers. Skin ulcers can cause the epidermis, dermis, and even subcutaneous fat to be lost completely ${ }^{[2]}$. Adults with chronic ulceration of the lower legs experience rising discomfort, friable granulation tissue, foul odour, and wound collapse rather than healing. As a consequence, there is socioeconomic distress as well as significant welfare and personal expenses ${ }^{[3]}$. Since lower leg ulcers are caused by a variety of causes, health providers must use an interdisciplinary approach to the systematic examination of the individual in order to determine the pathogenesis, a definitive diagnosis, and the best treatment options. A proper diagnosis is necessary to prevent ineffective care that can prolong wound healing, worsen the wound, or damage the patient. CLU is said to influence nearly every area of everyday life: pain is normal, sleep is frequently disrupted, mobility and job ability are often limited, and personal finances are frequently impacted ${ }^{[1,2]}$.

Chronic ulceration of the lower leg, including the foot, is a common disorder that causes pain, social distress, and costs a lot of money. The prevalence rate (for all ulcers) varies from $1 \%$ in the adult population to $3-5 \%$ in the population over 65 years old ${ }^{[4,5]}$. Lower limb ulcers caused by venous insufficiency account for $70 \%$ of cases, arterial disease $10 \%$, mixed aetiology ulcer $15 \%$, and lesser recognised pathophysiological triggers account for $5 \%$ of leg ulcers ${ }^{[6]}$ For, a rational approach towards patients with leg ulcers, it is important to have detailed knowledge about clinical picture, pathogenesis, diagnostic possibilities and treatment modalities of common
Corresponding Author: Assistant Professor, Chirayu Medical College \& Hospital, Bhopal, Madhya Pradesh, India 
causes, but at the same time to be aware of the large differential diagnosis of leg ulceration. Because an incorrect diagnosis usually leads to incorrect treatment and crucial time is lost leading to complications. Since numerous factors lead to lower leg ulceration, it is essential that health professionals adopt an interdisciplinary approach to the systematic assessment of the individual in order to ascertain the pathogenesis, a definitive diagnosis and early treatment.

\section{Material and methods}

This prospective cross sectional study which was carried in the Department of General Surgery after taking the approval of the protocol review committee and institutional ethics committee. A total of 100 patients were included who fulfilled study obligations.

\section{Inclusion and exclusion criteria}

All patients presenting with ulcer of the leg were included in the study. Patients unwilling to consent for the study were excluded.

\section{Methodology}

100 patients of chronic leg ulcers were selected randomly with the help of computer generated random numbers from the patients attending OPD or took admission in surgical ward.

Method of measurement of outcome of interest. The outcome of interest was morbidity and mortality of leg ulcer patients, the information of which was collected from case history sheet, relevant investigations and treatment. Limb salvage, amputation, poor control of diabetes mellitus, walking inability, poor pain management, recurrence of ulceration were considered as patient outcome. For calculation of risk factors likely to be associated with leg ulceration and calculation of patient outcome, patient's age, occupation (outdoor and indoor activities), smoking and drinking habits, presence of controlled or uncontrolled diabetes mellitus, ulcer location and characteristics, clinical examinations, arterial and venous circulation studies, biopsy of ulcer and medical and surgical treatments were taken into consideration.

Following the identification of the primary cause of leg ulcers, proper antibiotic coverage for gram positive, gram negative, and anaerobic organisms, proper glycaemic control, leg elevation, compression bandaging, complete cessation of smoking and causative drugs, nutritional support, vasoactive agents to restore blood flow, nerve stimulation, and proper wound care with debridement slough excision was recommended. Huge ulcers were considered for skin grafting as soon as the wound bed was ready. Care for venous insufficiencies, arterial disorder with lumbar sympathectomise/trans luminal angioplasty, and malignant ulcers were examined and workups were completed. Broad local excision, shallow radiotherapy, metastasis treatment, and multimodality treatment were all used to treat them. For non-healing/spreading/gangrenous/malignant ulcers, amputation was considered a last resort. In certain cases, rehabilitation of adjunctive footwear was given accordingly. To deter potential recurrence, education about proper foot care was given. The ulcer-free status of the patients was determined on the 7th and 21 st days after discharge.

\section{Statistical analysis}

Using this software, basic cross-tabulation and frequency distributions were prepared. T-test was used to compare the means. $\mathrm{P} \leq 0.05$ was considered statistically significant. with range 20-75 years and the median age was 52.0 years. Test of proportion showed that the proportion of the patients with age between $40-70$ years $(84 \%)$ was significantly higher $(Z=9.51$; $\mathrm{p}<0.0001$ ). Only $5 \%$ and $5 \%$ of the patients were with age $<30$ years and $\geq 70$ years respectively. Thus leg ulcers were more prevalent in the age group 40-70 years.

Test of proportion showed that proportion of males $85 \%$ was significantly higher than that of females $15 \% \quad(Z=9.74$; $\mathrm{p}<0.0001)$. Thus the leg ulcers were more prevalent among males.

Corrected chi-square test showed that there was no significant association between age and gender of the patients $(p=0.22)$. Thus the leg ulcers were evenly distributed over ages among both in males and females.

The mean (mean \pm SD) age of the male patients was $52.65 \pm 12.21$ years with range $20-75$ years and the median age was 52.0 years. The mean (mean \pm SD) age of the male patients was $53.16 \pm 13.55$ years with range $27-73$ years and the median age was 52.5 years (Table 1 ).

T-test showed that there was no significant difference between mean age of males and females $\left(\mathrm{t}_{191}=0.47 ; \mathrm{p}=0.60\right)$.

Table 1: Age and gender distribution

\begin{tabular}{|c|c|c|c|}
\hline Age group & \multicolumn{2}{|c|}{ Gender } & \multirow{2}{*}{ Total (\%) } \\
\cline { 1 - 3 } (in years) & Male & Female & 1 \\
\hline Below 20 & 1 & 0 & 4 \\
\hline $20-30$ & 3 & 1 & 6 \\
\hline $30-40$ & 6 & 0 & 26 \\
\hline $40-50$ & 20 & 6 & 30 \\
\hline $50-60$ & 26 & 4 & 28 \\
\hline $60-70$ & 22 & 6 & 5 \\
\hline Above 70 & 2 & 3 & 100 \\
\hline Total $(\%)$ & 80 & 20 & \\
\hline Mean \pm SD & $52.65 \pm 12.21$ & $53.16 \pm 13.55$ & \\
\hline
\end{tabular}

Chi square $=8.12 ; \mathrm{p}=0.23$ (not significant)

Most of the patients were engaged in agriculture (25\%) followed by business $(22 \%)$ and service $(14 \%)$.

$44 \%$ of the patients had habit of smoking, chewing tobacco and drinking of alcohol. Out of 44 patients having any kind of personal habit $12 \%$ had smoking followed by chewing tobacco (9\%), (Table 2).

Table 2: Distribution of personal habit

\begin{tabular}{|c|c|c|}
\hline Personal habit & Number & \% \\
\hline Smoking & 12 & 12 \\
\hline Chewing tobacco & 9 & 9 \\
\hline Smoking alcohol & 7 & 7 \\
\hline Smoking chewing tobacco alcohol & 6 & 6 \\
\hline Alcohol & 5 & 5 \\
\hline Chewing tobacco alcohol & 5 & 5 \\
\hline No habit & 56 & 56 \\
\hline Total & 100 & 100 \\
\hline
\end{tabular}

Ulcers in the left leg (49\% 0 was higher than that of right leg $(47 \%)$ but it was not significant $(Z=0.28 ; p=0.77)$. Only $3 \%$ of the patients were having ulcers in both legs.

Most of the patients $(61 \%)$ had ulcer at foot followed by gaiter $(20 \%)$ and leg $(19 \%)$. $(Z=6.14 ; p<0.0001)$.

Most of the ulcers were diabetic $(37 \%)$ followed by venous (22\%) $(\mathrm{Z}=2.31 ; \mathrm{p}=0.01)$. Only $5 \%$ and $3 \%$ were malignant and trophic ulcers (Table 3 ).

\section{Results}

The mean $($ mean \pm SD) age of the patients was $52.34 \pm 12.05$ years 
Table 3: Distribution of diagnosis of ulcers

\begin{tabular}{|c|c|c|}
\hline Diagnosis of ulcers & Number & \% \\
\hline Diabetic & 37 & 37 \\
\hline Venous & 22 & 22 \\
\hline Traumatic & 15 & 15 \\
\hline Arterial & 13 & 13 \\
\hline Malignant & 5 & 5 \\
\hline Trophic & 3 & 3 \\
\hline Others & 5 & 5 \\
\hline Total & 100 & 100 \\
\hline
\end{tabular}

Peripheral neuropathy (23\%) was the most common type of ulcer followed by venous hypertension $(22 \%)$. Only $1(1 \%)$ case of sickle cell disease was found (Table 4).

In $79 \%$ of the ulcers microorganisms were found which was significantly higher than that of no growth $(21 \%)(\mathrm{Z}=8.31$; $\mathrm{p}<0.0001)$. Out of the microorganisms Staphylococcus $(28 \%)$ was most common followed by Pseudomonas (14\%) and Klebsiella (11\%). Only in 2\% of the ulcers, Morgan Ella and $A F B$ were present (Table 5).

Most of the patients $(68 \%)$ had pain which was significantly higher than of no pain $(32 \%)(Z=5.16 ; p<0.001)$.

Table 4: Distribution of pathology of ulcers

\begin{tabular}{|c|c|c|}
\hline Pathology of ulcers & Number & $\%$ \\
\hline Peripheral neuropathy & 23 & 23 \\
\hline Venous hypertension & 22 & 22 \\
\hline Atherosclerosis & 14 & 14 \\
\hline Peripheral neuropathy atherosclerosis & 11 & 11 \\
\hline Trauma & 7 & 7 \\
\hline TAO & 6 & 6 \\
\hline SCC & 4 & 4 \\
\hline Bony defect & 3 & 3 \\
\hline Pressure sore & 3 & 3 \\
\hline Tubercular ulcer & 2 & 2 \\
\hline Vacuities & 2 & 2 \\
\hline Poor hygiene & 1 & 1 \\
\hline Leprosy & 1 & 1 \\
\hline Sickle cell disease & 1 & 1 \\
\hline Total & 100 & 100 \\
\hline
\end{tabular}

Table 5: Distribution of microorganisms

\begin{tabular}{|c|c|c|}
\hline Microorganisms & Number & $\%$ \\
\hline Staphylococcus & 28 & 28 \\
\hline Pseudomonas & 14 & 14 \\
\hline Klebsiella & 11 & 11 \\
\hline MRSA & 9 & 9 \\
\hline Streptococcus & 7 & 7 \\
\hline Proteus & 6 & 6 \\
\hline Morgan Ella & 2 & 2 \\
\hline Acid fast Bacilli & 2 & 2 \\
\hline No growth & 21 & 21 \\
\hline Total & 100 & 100 \\
\hline
\end{tabular}

Muscle (40\%) was the most common base of the ulcers followed bone $(27 \%)$ and subcutaneous tissue $(26 \%)$. Bone with tendon and only bone base was found in $7 \%$ of the cases. $(Z=1.41$; $\mathrm{p}=0.12$ ).

Table 6: Type of floor of ulcers

\begin{tabular}{|c|c|c|}
\hline Floor of ulcers & Number & $\%$ \\
\hline Unhealthy granulation tissue and slough & 36 & 36 \\
\hline Pale granulation tissue and slough & 22 & 22 \\
\hline Minimal slough & 18 & 18 \\
\hline Necrotic tissue & 7 & 7 \\
\hline Unhealthy granulation tissue & 5 & 5 \\
\hline Fresh granulation tissue & 4 & 4 \\
\hline Foul smelling slough & 3 & 3 \\
\hline Raised abnormal granulation tissue extending beyond the margin & 3 & 3 \\
\hline Total & 2 & 2 \\
\hline
\end{tabular}

Most of the floors of the ulcers were unhealthy granulation tissue and slough $(36 \%)$ followed by pale granulation tissue and slough $(22 \%)$. Only in $2 \%$ of the cases it was raised abnormal granulation tissue extending beyond the margin. $(\mathrm{Z}=2.01$; $\mathrm{p}=0.02$ ), (Table 6).

$55 \%$ of the ulcers had shallow edge followed by sloping $(21 \%)$
$(\mathrm{Z}=5.05 ; \mathrm{p}<0.001)$. Only $2 \%$ was undermined. Most of the margin of the ulcers were irregular $(38 \%)$ which was significantly higher $(\mathrm{Z}=2.37 ; \mathrm{p}=0.0127)$ followed by thin bluish irregular (22\%). Only $3 \%$ of the margin of ulcers was regular. $22 \%$ of the surrounding area was lipodermatosclerosis and hyper-pigmentation with itching. $32 \%$ of the discharge was 
slough with purulent discharge followed by serous $(26 \%)$. In most of the cases debridement with dressing (30\%) was done

(Table 7).

Table 7: Type of surgical management

\begin{tabular}{|c|c|c|}
\hline Surgical management & Number & $\%$ \\
\hline Debridement dressing & 30 & 30 \\
\hline Debridement dressing skin grafting & 12 & 12 \\
\hline Debridement dressing disarticulation & 11 & 11 \\
\hline Stripping Gsv/Ssv hook phlebotomy & 10 & 10 \\
\hline Hook phlebotomy & 8 & 8 \\
\hline Stripping Gsv/Ssv & 5 & 5 \\
\hline Id debridement trans metatarsal amp & 5 & 5 \\
\hline Debridement dressing below knee amputation angiography balloon angioplasty & 4 & 4 \\
\hline Wide excision skin grafting & 3 & 3 \\
\hline Debridement dressing lumbar-sympathectomise & 2 & 2 \\
\hline Debridement dressing metatarsal amputation angiography balloon angioplasty & 2 & 2 \\
\hline Debridement skin grafting dressing & 2 & 2 \\
\hline Debridement dressing below knee amputation & 1 & 1 \\
\hline Below knee amputation & 1 & 1 \\
\hline Midthigh amputation & 1 & 1 \\
\hline Debridement dressing angiography balloon angioplasty skin grafting & 1 & 1 \\
\hline Debridement dressing angiography balloon angioplasty & 1 & 1 \\
\hline Debridement dressing Midthigh amputation & 1 & 1 \\
\hline Total & 100 & 100 \\
\hline
\end{tabular}

Most $(57 \%)$ of the ulcers were in the Grade-II followed by Grade-III (35\%). Only 1\%, $2 \%$ and $5 \%$ were in the grade of V, I and IV respectively $(\mathrm{Z}=3.12 ; \mathrm{p}=0.0021)$, (Table 8$)$.

Table 8: Status at last contact

\begin{tabular}{|c|c|c|}
\hline Status at last contact & Number & \% \\
\hline Healed & 93 & 93 \\
\hline Dead & 3 & 3 \\
\hline Disease Free & 3 & 3 \\
\hline Recurred & 1 & 1 \\
\hline Total & 100 & 100 \\
\hline
\end{tabular}

\section{Discussion}

A proportion test revealed that the proportion of patients aged 40 to 70 years $(84 \%)$ was slightly higher $(Z=9.51$; 0.0001$)$ in this sample. Just $5 \%$ and $5 \%$ of the patients were under the age of 30 and 70 years, respectively. As a result, leg ulcers were more common in people aged 40 to 70 . In their research, Cornwall et al. discovered that $70 \%$ of the patients were over the age of 70 , and Callam et al. discovered that ulceration started before the age of 40 in $22 \%$ of the patients ${ }^{[7,8]}$.

The proportion of males who were 85 percent was slightly higher than the proportion of females who were 15 percent $(\mathrm{Z}=9.74$; 0.0001$)$. As a result, males were more likely to develop leg ulcers.

According to different studies, females are more likely than males to develop chronic leg ulcers ${ }^{[7,8]}$. Male predominance was observed in our sample, with a male to female ratio of 5.67:1. A hospital-based survey in India found a male-to-female ratio of 5.7:1, which is close to the male-to-female ratio in the United States ${ }^{[9]}$. This may be because of the fact that in India males are more engaged in outdoor activities compared to female who remain indoors.

Corrected Chi-square test showed that there was no significant association between age and gender of the patients $(p=0.22)$. Thus the leg ulcers were evenly distributed over ages among both in males and females.

The mean (mean \pm SD) age of the male patients was $52.65 \pm 12.21$ years with range $20-75$ years and the median age was 52.0 years. The mean (mean $\pm \mathrm{SD}$ ) age of the male patients was $53.16 \pm 13.55 y$ years with range $27-73$ years and the median age was 52.5 years.

T-test showed that there was no significant difference between mean age of males and females $\left(\mathrm{t}_{191}=0.47 ; \mathrm{p}=0.60\right)$.

No significant difference between sexes was found when age specific relative frequencies were compared $(\mathrm{H}=2.5357, \mathrm{DF}=4$, $\mathrm{p}=0.6383$ ) in a study conducted in India ${ }^{[10]}$.

Most of the patients were engaged in agriculture (25\%) followed by business $(22 \%)$ and service $(14 \%)$.

As per the study conducted in China majority of leg ulcers were among the farmers and agricultural workers as in the present study ${ }^{[11]}$.

$44 \%$ of the patients had habit of smoking, chewing tobacco and drinking of alcohol. Out of 44 patients having any kind of personal habit $12 \%$ had smoking followed by chewing tobacco (9\%). In a study on Indian patients found that there is a positive relationship between smoking and diabetes ${ }^{[12]}$. Cigarette smoking has been reported to have an impact on wound healing through impairment of tissue oxygenation and local hypoxia via vasoconstriction ${ }^{[13]}$. Tobacco smoke has high concentration of carbon monoxide, which binds haemoglobin, forming carboxyhemoglobin. Carboxyhemoglobin binds to oxygen with high affinity and thereby interferes with normal oxygen delivery to hypoxic tissues ${ }^{[14]}$. Higher proportion of patients with smoking and drinking habit may be associated with greater population of diabetic leg ulcers in our study.

Ulcers in the left leg (49\% 0 was higher than that of right leg $(47 \%)$ but it was not significant $(\mathrm{Z}=0.28 ; \mathrm{p}=0.77)$. Only $3 \%$ of the patients were having ulcers in both legs.

In a study from Nigeria showed 17 ulcers on Left leg $(51.5 \%)$, 15 ulcers on right leg (45.5\%) and 1 (3\%) ulcer on both leg in a population of 33 patients. But laterality of leg ulceration has no impact on the outcome of leg ulcer ${ }^{[15]}$.

Most of the patients $(61 \%)$ had ulcer at foot followed by gaiter $(20 \%)$ and leg (19\%). ( $Z=6.14 ; p<0.0001)$. Our study was conducted in a government district hospital where most of the patients seeking medical advice belong to lower socioeconomic class. Beedi smoking is prevalent in lower socioeconomic class people who also walk and work bare footed, so more vulnerable to trauma to foot. Poor education and poverty prevents them to 
attend health care facility promptly.

Most of the ulcers were diabetic (37\%) followed by venous $(22 \%)(\mathrm{Z}=2.31 ; \mathrm{p}=0.01)$. Only $5 \%$ and $3 \%$ were malignant and trophic ulcers. Distribution of different type of ulcers in different studies varies $70 \%$ to $90 \%$ for venous ulcer, $5 \%$ to $15 \%$ for arterial ulcers and $1 \%$ to $5 \%$ for other ulcers ${ }^{[16]}$. All of these are based on population in western countries. But Indian study in prevalence of leg ulcer is limited to only one hospital based study. The study suggested that leprosy $(40 \%)$, diabetes $(23 \%)$, venous disease $(11 \%)$, and trauma $(13 \%)$ were among the causes of lower extremity wounds in patients attending that hospital. Thirteen percent of wounds were not directly linked to any known cause ${ }^{[8]}$. Arterial ulcer is seen among $13 \%$ patient in our study. In region where our hospital is present, prevalence of tobacco usage is about $50-65 \%$ in the population ${ }^{[17]}$. Higher rate of smoking and use of tobacco products, especially use of Beedi smoking in Indian male could be the cause of more number of male patients compared to female and higher number of arterial ulcer in our study ${ }^{[18]}$. Also incidence Burger's disease among peripheral arterial disease is more in India (45-63\%) than Europe $(0.5-5.6 \%)^{[19]}$. Beedi smoking is prevalent in lower socioeconomic class people who also walk bare footed, so more vulnerable to trauma to foot. Poor education and poverty prevents them to attend health care facility promptly. The above mentions causes may be the reason of more arterial ulcer in our study. Venous ulcers are significantly lower in our study $(22 \%)$ compared to western studies. Only one study available in literature done by Malhotra on prevalence of varicose veins in Indian population, which showed the prevalence of varicose vein in rail road workers found to be $25.08 \%$ in south Indian and $6.8 \%$ in north Indian workers ${ }^{[20]}$. Leg ulcer due to malignancy, tuberculosis, neurotropic causes are seen rarely.

Peripheral neuropathy (23\%) was the most common type of ulcer followed by venous hypertension (22\%). Only 1 (1\%) case of sickle cell disease was found. In a community-based study from Chennai, south India, Pradeepa et al. measured the prevalence of DPN using VPT by biothesiometer. The prevalence in newly diagnosed patients was $19.5 \%$ and $27.8 \%$ in those with known diabetes ${ }^{[21]}$. However, the frequency of DPN in the subjects without diabetes was not studied. The higher proportion of peripheral neuropathy is due to higher proportion of diabetic leg ulcers in our study.

In $79 \%$ of the ulcers microorganisms were found which was significantly higher than that of no growth $(21 \%)(\mathrm{Z}=8.31$; $\mathrm{p}<0.0001)$. Out of the microorganisms Staphylococcus $(28 \%)$ was most common followed by Pseudomonas (14\%) and Klebsiella (11\%). Only in 2\% of the ulcers, Morgan Ella and $A F B$ were present. Similar result was reported by Mathangi et al. in their study ${ }^{[22]}$.

Most of the patients $(68 \%)$ had pain which was significantly higher than of no pain $(32 \%)(Z=5.16 ; p<0.001)$. Similar study was reported by Hassan Ghassemi et al. ${ }^{[10]}$.

Most of the ulcers were muscle deep containing unhealthy granulation tissue and slough with serous or purulent discharge, irregular or thin bluish margins, shallow edge followed by sloping edge, associated with lipodermatosclerosis and hyperpigmentation or induration. These findings were associated with more numbers of diabetic and venous leg ulcer patients in this present study.

\section{Conclusion}

As a result, the current research concluded that different cases of leg ulcers arouse a great deal of curiosity and are perplexing in terms of care. There has undoubtedly been a significant increase in the treatment of untreated leg ulcers, thanks to the availability of an array of investigational antibiotics and ever-improving dressing materials.

\section{Reference}

1. Kahle B, Hermanns HJ and Gallenkemper G, "Evidence based treatment of chronic leg ulcers", Deutsches Arzteblatt International. 2011;108(14):231-237.

2. Van Gent WB, Wilschut ED and Wittens C. "Management of venous ulcer disease", The British Medical Journal. 2010;341(7782):1092-1096.

3. Gonzalez-Consuegra RV and Verd J "Quality of life in people with venous leg ulcers: an integrative review", Journal of Advanced Nursing. 2011;67(5):926-944.

4. Ryan TG. The epidemiology of leg ulcers in diagnosis and treatment (Westerh of W, Ed). Amsterdam: Elsevier science Publishers BV, 1993, 19-27.

5. Baker SR, Stacey MC, Jopp-McKay AG et al. Epidemiology of chronic venous ulcers $\mathrm{Br} \quad \mathrm{J}$ Surg 1991;78:864-7

6. Casey G. Causes and management of leg and foot ulcers Nursing Standard. 2005; 23:601-611.

7. Cornwall JV, Dore CJ, Lewis JD. Leg Ulcers: Epidemiology and aetiology Br J Surg. 1986;73:693-6.

8. Callam MJ, Harper DR, Dale JJ, Ruckley CV. Chronic ulcer of leg: Clinical history BMJ. 1987;294:1389-91.

9. Saraf SK, Shukla VK, Kaur P, Pandey SS. A clinic epidemiological profile of non- healing wounds in an Indian hospital, J Wound Care. 2000;9:247-50.

10. Ghassemi H. Assessment of etiological factors in chronic leg ulcers in Indian population IJRCD. 2016;2(1):89-93.

11. Fu X. Skin ulcers in lower extremities: The epidemiology and management in China, Int. $\mathbf{J}$ of lower Ext wounds. 2005;4(1):4-6.

12. Morton G, Garret M, Reid J, Wingrad D. Current Smoking and Type 2 Diabetes among patients in selected Indian health service clinics, 1998-2003, Am J Public Health. 2008;98:560-5.

13. Jone SK, Tripleff RG. The relationship of cigarette smoking to impaired intra-oral wound healing: A review evidence and implication for patient care, J Oral Maxillo Surg. 1992;50:237-40.

14. Nagachinta T, Stephens M, Reitz B, Polk BF. Risk factors for surgical wound infection Muisory cardiac surgery S Inf Dis. 1987; 156:967-73.

15. Adigun IA, Rahman GA, Fadeyi A. Chronic leg ulcer in the older age group: Etiology and management Res J Med Sci. 2010;4(3):107-110.

16. Korber A, Klode J, Al Benna S, Wax C, Schadendorf D, Steinstraesser L et al. Etiology of chronic leg ulcers in 31,619 patients in Germany analyzed by an expert survey, J Dtsch Dermatol Ges. 2011;9(2):116-21.

17. WHO. Report on the Global Tobacco Epidemic, The MPOWER package. Geneva, World Health Organization, 2008.

18. Gupta PC, Asma S. Bidi Smoking and Public Health, New Delhi: Ministry of health and family welfare, Government of India, 2008, 145.

19. Arkkila PE. Thromboangitis obliterans (Berger's disease), Orphanet J Rare Dis. 2006;1:14.

20. Malhotra SL. An epidemiological study of varicose veins in Indian railroad workers from south and north of India, with reference to the causation and prevention of varicose veins, Int J Epid. 1972;1:177-83. 
21. Pradeepa R, Rema M, Vignesh J, Deepa M, Deepa R, Mohan V. Prevalence and risk factors for diabetic neuropathy in an urban south Indian population: The Chennai Urban Rural Epidemiology Study (CURES-55) Diabet Med. 2008;25:407-12.

22. Mathangi T, Prabhakaran P. Prevalence of Bacteria Isolated from Type 2 Diabetic Foot Ulcers and the Antibiotic Susceptibility Pattern, Int. J Curr. Microbiol. App Sci. 2013;2(10):21-5. 